\title{
SERVIÇOS DE TÁXI: ASPECTOS JURÍDICOS CONTROVERTIDOS E MODELOS REGULATÓRIOS
}

\section{TAXI SERVICES: CONTROVERTIAL LEGAL ASPECTS AND REGULATORY MODELS}

\section{Thiago Marrara ${ }^{1}$}

\begin{abstract}
Resumo
O presente artigo traz reflexões iniciais sobre a relevância da mobilidade urbana para o cumprimento das funções primárias da cidade. A partir dessa premissa, aborda aspectos macrojurídicos dos serviços de transporte urbano no Brasil para então ingressar no exame das normas sobre serviços de táxi, hoje previstas na Lei de Mobilidade Urbana. Nesse particular, mostra-se como o direito nacional modificou a natureza jurídica dos serviços de táxi e congêneres e debatem-se aspectos atuais sobre a regulação da entrada, da qualidade e dos preços desses serviços privados de interesse público. Com base nisso, mostra-se que os Municípios não são forçados pela legislação nacional a seguir um único modelo regulatório e, ao final, comparam-se as vantagens e desvantagens de dois modelos licitatórios hipotéticos.
\end{abstract}

Palavras-chaves: mobilidade urbana; transporte; táxi; lei de mobilidade

\begin{abstract}
This article brings some considerations on the relevance of urban mobility as a condition to the accomplishment of primary cities functions. Based on this assumption, it points out legal aspects on a broader perspective regarding urban transportation services in Brazil and then it addresses specifically the legal framework of taxi services, which are subject to the Urban Mobility Act. On this point, it demonstrates how national Law has changed the legal nature of taxi services and, based on the actual legal provisions, it debates contemporary aspects regarding the regulation of entry, quality and prices of theses so called private services of public interest. On that basis, the article also shows that legal Governments in Brazil are not forced by the National Mobility Act to adopt a unitary regulatory model and, at the end, it compares two possible regulatory scenarios, considering their advantages and disadvantages.
\end{abstract}

Keywords: urban mobility; transportation; taxi; Mobility Act

\footnotetext{
${ }^{1}$ Professor, de graduação e pós-graduação, nas áreas de direito administrativo, urbanístico, ambiental junto ao Departamento de Direito Público da Nova Faculdade de Direito da USP (FDRP). Livre-docente em direito administrativo pela FD (USP), doutor em direito público pela Ludwig Maximilians Universität (LMU) de Munique, Alemanha. Editor-gerente da Revista Digital de Direito Administrativo (RDDA) da USP, coordenador do grupo de pesquisa de direito administrativo (GDA), organizador do Seminário de Pesquisa de Direito Administrativo (SPDA), bem como pesquisador e membro do conselho deliberativo do Centro de Estudos em Direito e Desigualdades (CEDD). Pesquisador visitante no Max Planck Institut für Innovation und Wettbewerb (Alemanha), no Centre de Recherches Administratives da Universidade de Aix-Marseille (França), na Faculdade de Direito da Universidade Autônoma de Madrid (Espanha). E-mail: marrara@usp.br
} 


\section{INTRODUÇÃO: A MOBILIDADE E A CIDADE}

Por que nos juntamos em cidades? Eis a pergunta central que necessita ser retomada antes que se discuta a mobilidade urbana e se aborde a problemática da prestação e da regulação dos serviços de transporte no Brasil com especial atenção para os serviços de táxi e análogos.

Conquanto os limites entre urbano e rural tornem-se cada dia mais sutis e imprecisos, há uma diferença crucial entre a cidade e o campo. Como fenômeno social, geográfico e cultural, a cidade se caracteriza por uma concentração de indivíduos em um espaço relativamente limitado e à qual se somam paulatinamente atividades econômicas, culturas, modos de vida, instituições próprias, além de uma densa infraestrutura física. Na versão mais poética de Jacqueline BeaujeuGarnier (1997, p. 47), defensora da concepção de sistema urbano,

A cidade é constituída por essa mistura, por estes aspectos múltiplos: um esqueleto de pedra, tijolo ou cimento; homens que se acotovelam em atividades infinitamente diversas, o poder da concentração, a multiplicação das possibilidades, dos recursos, do conflito, do progresso, uma forma de civilização em marcha.

A concentração de indivíduos faz das cidades o espaço dos fluxos e das trocas. Afinal, em um terreno reduzido e densamente povoado, as trocas são facilitadas e barateadas, daí porque se diz que a urbanização gera economias de concentração, ou seja, reduções de custos que derivam do adensamento e da proximidade populacional em seu território.

O espaço urbano dos fluxos não se limita apenas ao campo do comércio, do setor terciário, da economia. O urbano é marcado pelo rápido intercâmbio de afeto, de relações, de informações, valores, conhecimentos e culturas. Até pouco tempo, antes de se construírem e de se consagrarem redes digitais globais e espaços de trocas no ambiente virtual, as cidades constituam o meio soberano das trocas, dos fluxos e do desenvolvimento de relações sociais, econômicas e culturais muitas delas juridicamente reguladas.

Como espaço de contatos, fluxos e trocas das mais variadas naturezas, a função primária da cidade consiste em permitir que os indivíduos busquem e atinjam aquilo que consideram relevante para satisfazer suas necessidades econômicas, sociais e individuais. E não poderia ser diferente, já que os indivíduos não se reúnem em cidades para degradar seu bem-estar. Tomandose como premissa sua racionalidade de ação, eles se agregam no território urbano e nele influem exatamente pelo objetivo oposto: melhorar suas condições de vida, sua interação, seus contatos, sem bem-estar. 
Para que a cidade cumpra minimamente sua função primária essencial como espaços dos fluxos, ${ }^{2}$ mostra-se imperioso que alguns requisitos sejam preenchidos: 1) há que se oferecer uma infraestrutura física adequada para a circulação e a interação no espaço urbano (aspecto geográfico); 2) é preciso que os custos de interação não sejam elevados (aspecto econômico) e 3) que o ambiente urbano seja seguro e saudável (aspecto socioambiental - a respeito do qual vale a consulta à obra de Carmona, 2014, em geral).

Sob a perspectiva jurídica, na medida em que se garantem todas essas condições de maneira satisfatória, o espaço urbano se transforma em um local de intensiva concretização de direitos. De outro lado, quando os requisitos em tela são ignorados ou cumpridos de modo deficiente, o espaço urbano passa a bloquear e a prejudicar direitos. A cidade perde seu sentido, sua função primária, sua razão de existir. O sistema urbano adoece.

É nessa relação entre espaço urbano, fluxos e direito que ganha relevância o tema da mobilidade e também dos serviços de transporte, como os de táxi. Para evidenciar essa afirmação, nesse breve ensaio, parte-se de considerações e reflexões acerca do papel da mobilidade para a concretização da função urbana, apontam-se os tipos básicos de transporte previstos na Lei de Mobilidade e, ao final, ingressa-se na discussão do tema central de estudo: o serviço de transporte individual de interesse público, de que são exemplos os serviços de táxi, e seu regime jurídico, com especial destaque para as normas que o regulam.

\section{MOBILIDADE, FUNÇÃO URBANA E RENÚNCIA À CIDADE}

Para que a cidade cumpra a função essencial que seus habitantes esperam e promova economias de concentração no desenvolvimento das trocas, fluxos e interações, é preciso que a locomoção dos indivíduos e de suas cargas ocorra de maneira simples, fácil, segura e barata no

\footnotetext{
${ }^{2}$ Como há tempo esclareceu Milton Santos (2002, p. 275) ao tratar da relação do espaço com o imperativo da fluidez no mundo atual, "não basta, pois, produzir. É indispensável por a produção em movimento. Em realidade, não é mais a produção que preside à circulação, mas é esta que conforma a produção". Essa lógica explica muito da relevância adquirida pela mobilidade na contemporaneidade.

${ }^{3}$ Sobre o papel da infraestrutura urbana para a viabilização das funções sociais essenciais da cidade, Thiago Marrara explica que "a constituição de um sistema urbano e o cumprimento de sua função social... depende de inúmeras relações econômicas, sociais e jurídicas, e o bom desenvolvimento destas relações apoia-se diretamente na existência de elementos físicos, concretos ou reais, dentre os quais estão os bens que compõem o domínio público urbano" (2007, p. 162). E complementa: "tal é a importância destes elementos físicos, dentre os quais os componentes do domínio urbano, que o direito brasileiro os tornou condição para a identificação da zona urbana. Como ensinou Meirelles, tanto é assim que a determinação da zona urbana por lei municipal específica não teria qualquer validade se não se confirmasse a existência de elementos físicos na área geográfica considerada" (2007, p. 163).
} 
tecido urbano. Essas são as características ideais da locomoção no espaço urbano. Não basta, portanto, qualquer mobilidade, mas a mobilidade adequada, ${ }^{4}$ ou seja, caracteriza pelos quatro adjetivos acima pontuados.

Há, porém, alguns fatores que dificultam a oferta de condições ideais de mobilidade.

Em primeiro lugar, é possível que as cidades se expandam intensivamente do ponto de vista demográfico e territorial, de modo que os percursos necessários para as trocas e as interações se tornem excessivos e, ao final, desestimulem a locomoção e a circulação. Isso se vislumbra muito facilmente em capitais de países em desenvolvimento, nas quais as dificuldades de mobilidade impõem técnicas de adaptação para fins de obtenção de um mínimo de qualidade de vida, como a busca de moradia próxima ao trabalho e a restrição das relações sociais ao espaço do bairro em que se habita.

Em segundo lugar, ainda que a cidade não se alargue espacialmente, seu mero adensamento populacional, por fatores naturais ou extraordinários, pode gerar o estrangulamento ou o esgotamento das vias de locomoção por conta do transporte individual ou do transporte público existentes. Nessas situações, dada a escassez da infraestrutura de transporte, a interação se dificulta não pelo aumento dos percursos, mas pelos constrangimentos e incômodos causados pelo uso intensivo e esgotante das vias, seja em meio de transporte público ou individual.

Em ambas as hipóteses exemplificativas, os efeitos negativos se igualam: a facilidade de fluxo se reduz, as econômicas de concentração que justificam a existência dos espaços urbanos desaparecem, os custos de interação e de locomoção aumentam e o exercício de direitos fundamentais urbanos sofre graves restrições. Os impactos negativos da falta de mobilidade levam, nas situações mais extremas, à renúncia do indivíduo à própria cidade, a qual se manifesta tanto pela desistência de uso do espaço urbano, quanto pela emigração.

Para que todos esses efeitos sejam controlados e combatidos e para que a queda de mobilidade não culmine na renúncia à cidade, torna-se fundamental a ação proativa do Estado

\footnotetext{
${ }^{4}$ Não constitui objetivo central do texto desenvolver o conceito de mobilidade. Assim, apenas para fins explicativos, toma-se aqui a definição oferecida alhures no seguinte sentido: "mobilidade urbana, por conseguinte, designa o grau de movimento possível na cidade, ou melhor, a facilidade com a qual pessoas se locomovem e cargas são transportadas no tecido urbano. Quanto maior a mobilidade, mais simples e rápida se supõe que seja a movimentação de pessoas e objetos" (MARRARA, 2015, p. 122). Nas palavras de Lígia Casimiro e José Melo, "a mobilidade urbana é a possibilidade real das condições de deslocamento das pessoas dentro do território urbano, ainda que os mesmos lá não habitem, permitindo que os cidadãos possam realizar suas necessidades e acessar bens e serviços, sejam os mesmos públicos ou privados" (CASIMIRO; MELO, 2015, p. 147). A respeito, cf. também GUIMARÃES, 2012, p. 191.
} 
quer no desenvolvimento de políticas nacionais de mobilidade urbana, quer pela adoção de medidas concretas no âmbito de cada Município.

Atenta ao problema, a Constituição da República de 1988 atribuiu à União as competências de: a) executar planos nacionais e regionais de ordenação do território, bem como de instituir diretrizes para o desenvolvimento urbano, inclusive habitação, saneamento básico e transportes (art. 21, incisos IX e XX) e b) legislar sobre as diretrizes da política nacional de transporte e sobre trânsito e transporte (art. 22, incisos X e XI). Ao Município, por sua vez, a Constituição conferiu as tarefas de: a) organizar e prestar, direta ou indiretamente, os serviços públicos de interesse local, incluído o de transporte público, que desempenha caráter essencial, e de promover o adequado ordenamento territorial (art. 30, V e VIII) e b) desenvolver uma política desenvolvimento urbano que garanta as funções sociais da cidade e o bem-estar de seus habitantes (art. 182, caput).

\section{Os tipos de transporte na Lei de Mobilidade}

O texto constitucional, de maneira evidente, considera os transportes (e, por reflexo, a mobilidade) essencial ao desenvolvimento urbano e o bem-estar da população. A partir dos mandamentos constitucionais antes apontados, o Congresso editou a Lei de Mobilidade Urbana (Lei n. 12.587/2012), a qual deu especial destaque à gestão dos transportes como ferramenta necessária à viabilização da mobilidade adequada nas cidades.

Apesar de a Lei apresentar conteúdo excessivamente descritivo, classificatório e conceitual em grande parte de seu texto - o que se explica pela Competência da União para editar diretrizes e normas gerais sobre a matéria -, a padronização dos tipos de serviços de transporte que foi por ela trazida mostra-se bastante relevante. Em poucas palavras, subjacentes à classificação legal encontram-se critérios que se apoiam no objeto transportado, na natureza jurídica do transporte e na sua função privada ou coletiva. ${ }^{5}$ Nesse sentido, o transporte urbano se divide pela lei nacional em transporte de carga ou de passageiros. Este, por seu turno, subdivide-se em: a) transporte privado individual; b) transporte privado coletivo; ${ }^{6}$ c) transporte público individual e d) transporte público coletivo.

\footnotetext{
${ }^{5}$ Em sentido semelhante, cf. GROTTI, 2015, p. 88.

${ }^{6} \mathrm{O}$ transporte privado coletivo basicamente se resume ao fretamento. A tal respeito, explica Dinorá Grotti que: "o transporte de passageiros por fretamento desempenha um papel relevante na mobilidade das pessoas por razões de trabalho, de educação ou de lazer. Constitui, ademais, uma alternativa ao uso do automóvel ou da motocicleta, uma vez que acarreta menor consumo de espaço viário e menor emissão de poluentes, colaborando para a redução dos níveis de congestionamento. O argumento prevalecente para
} 
Desses quatro meios de transporte urbano de passageiros, maior destaque foi conferido ao transporte público coletivo, haja vista sua irrefragável relevância social e sua enorme conveniência urbanística do ponto de vista ambiental e espacial, já que ele permite o deslocamento de um número significativamente alto de indivíduos, mas mediante uso de espaço muito menor que o necessário para o transporte individual. ${ }^{7}$

No intuito de valorizar o transporte público coletivo, serviço público de competência primariamente municipal, a Lei de Mobilidade traçou algumas diretrizes que devem ser seguidas pelos Poderes Públicos locais ao elaborarem suas políticas de mobilidade. Os art. 8o e 10 da Lei, entre outras coisas, indicam como diretrizes: a necessidade de se garantir a acessibilidade e a ocupação equilibrada da cidade; a transparência e simplicidade na prestação do serviço; a modicidade da tarifa cobrada (nos casos de execução indireta por concessionário ou permissionário, salvo quando houver gratuidade); a busca da integração física, tarifária e operacional dos prestadores e dos meios de transporte; a articulação federativa, sobretudo em áreas metropolitanas e a obrigatoriedade da adoção de metas de qualidade, as quais devem ser estimuladas pela previsão de penas e incentivos em relação a executores indiretos desses serviços.

Não interessa a esse estudo, contudo, o aprofundamento do transporte público coletivo, mas sim a análise do regime jurídico dos serviços de táxi e seus congêneres.

\section{O TRANSPORTE POR TÁXI: TRADICIONAL, FIXO E POR SOLICITAÇÃO REMOTA}

Ao construir a Lei Nacional de Mobilidade, o legislador reputou necessário inserir diretrizes gerais para a execução do serviço de transporte público individual de passageiros, ou seja, para serviços de táxi. É verdade que tais serviços não se caracterizam pela acessibilidade financeira e pelas vantagens espaciais que marcam o serviço de transporte público coletivo, mas ainda assim foram considerados relevantes por algumas razões que merecem registro.

A uma, os serviços de transporte público individual possibilitam viagens personalizadas e, com isso, cobrem trajetos e horários não necessariamente realizados pelo transporte coletivo, conferindo flexibilidade e maior capilaridade ao sistema de transporte. A duas, tais serviços são capazes de gerar, sob certas condições, benefícios espaciais e ambientais, sobretudo porque

restringir o uso do transporte por fretamento é a constatação, com frequência, de estacionamento dos veículos de forma irregular ou errônea, atravancando o trânsito" (GROTTI, 2015, p. 89).

${ }^{7}$ Em mais detalhes sobre o transporte público coletivo, cf. MARTINS (2015, p. 191) e MARRARA (2015, p. 131 e seguintes). 
reduzem a necessidade de espaço urbano para estacionamento de veículos individuais próprios em certas regiões.

Esses e outros benefícios são hipotéticos, diga-se bem! Na prática, as vantagens concretas dos serviços de táxi variam conforme o modo como ele é prestado no contexto urbano. A esse respeito, há que se aludir a pelo menos três formas de prestação: ${ }^{8}$ a) a tradicional, pela qual os taxis circulam pelas ruas aleatoriamente até que sejam abordados por passageiros potenciais, modelo no qual o serviço acaba contribuindo para a degradação ambiental e para o estrangulamento das vias públicas (isso em razão do aumento de veículos sem passageiros nas ruas e da queima inútil de combustível); b) a fixa, na qual os taxis aguardam em pontos específicos distribuídos pela cidade, aos quais os passageiros se dirigem quando interessados no serviço, evitando-se assim a circulação aleatória dos veículos e reduzindo-se os impactos ambientais e econômicos do primeiro modelo e c) o transporte por solicitação remota, no qual o potencial passageiro, localizado em ponto geográfico distinto ao do transportador, entra em contato para solicitar seus serviços por meio de inúmeras tecnologias de comunicação, desde o telefone, passando pelo e-mail ou aplicativos de celulares.

\section{REGULAÇÃO DOS SERVIÇOS DE TÁXI: O ART. 12 DA LEI DE MOBILIDADE}

Ainda que não tenha feito menção expressa a essas três formas de prestação do serviço de táxis e congêneres, a Lei de Mobilidade não desprezou os serviços em questão. Nomeadamente com o objetivo de contribuir com a formulação de políticas de mobilidade adequada no país, ela estabeleceu diretrizes básicas sobre tais serviços - diretrizes essas que, por constarem de normas nacionais, atingem todos os entes da federação.

No tratamento do assunto, as normas da Lei de Mobilidade de 2012 foram logo alteradas em 2013 e, mais tarde, em 2015. Referidas alterações mostraram-se significativas, na medida em que atingiram a natureza jurídica do serviço em questão e geraram novas dúvidas sobre seu regime jurídico e, igualmente, sobre as opções dos Municípios no desenvolvimento de políticas públicas específicas para esse modo de transporte urbano.

Na redação originária da Lei de Mobilidade, havia apenas o art. 12, que assim dispunha:

\footnotetext{
${ }^{8}$ Nesse sentido, mas valendo de outra terminologia ("segmento de pontos de táxi", "segmento de rua" e "segmento porta a porta"), cf. o estudo de ESTEVES (2015, p. 20).
} 
Art. 12. Os serviços públicos de transporte individual de passageiros, prestados sob permissão, deverão ser organizados, disciplinados e fiscalizados pelo poder público municipal, com base nos requisitos mínimos de segurança, de conforto, de higiene, de qualidade dos serviços e de fixação prévia dos valores máximos das tarifas a serem cobradas.

A partir da redação transcrita, hoje revogada, observa-se que o legislador considerava os serviços de táxis como espécie de serviço público municipal. Nessa qualidade, não havia dúvida de que o serviço poderia ser prestado diretamente pelo Poder Público local ou indiretamente por particulares. Para fins de delegação, a Lei de Mobilidade ainda impunha de modo explícito a adoção do instrumento da permissão, celebrado com cada prestador e - supunha-se - precedido de algum tipo de procedimento racional de escolha dos prestadores.

Naquele contexto normativo, o serviço era monopolizado pelo Município e a entrada de novo prestador nesse mercado somente ocorria caso lograsse celebrar a referida permissão. Havia, pois, um comando normativo nacional para o controle de entrada de competidores no setor. Fora isso, impunha-se uma regulação de qualidade (segurança, conforto, higiene etc.), bem como a regulação de preço, mediante a fixação de tarifas máximas que seriam cobradas pelos prestadores indiretos.

Em pouquíssimo tempo, contudo, esses mandamentos foram alterados de forma significativa. A Lei n. 12.865 de 2013 conferiu nova redação do art. 12 originário e, além disso, inseriu o art. 12-A, com três parágrafos, na Lei de Mobilidade. Vale a transcrição:

Art. 12. Os serviços de utilidade pública de transporte individual de passageiros deverão ser organizados, disciplinados e fiscalizados pelo poder público municipal, com base nos requisitos mínimos de segurança, de conforto, de higiene, de qualidade dos serviços e de fixação prévia dos valores máximos das tarifas a serem cobradas.

Art. 12-A. O direito à exploração de serviços de táxi poderá ser outorgado a qualquer interessado que satisfaça os requisitos exigidos pelo poder público local. § 1 ㅇ É permitida a transferência da outorga a terceiros que atendam aos requisitos exigidos em legislação municipal. § 2o Em caso de falecimento do outorgado, o direito à exploração do serviço será transferido a seus sucessores legítimos, nos termos dos arts. 1.829 e seguintes do Título II do Livro V da Parte Especial da Lei $n^{\circ}{ }_{-}$10.406, de 10 de janeiro de 2002 (Código Civil). § 3 o As transferências de que tratam os $\S \S 1$ e $2 ㅇ ㅡ$ dar-se-ão pelo prazo da outorga e são condicionadas à prévia anuência do poder público municipal e ao atendimento dos requisitos fixados para a outorga.

De acordo com Dinorá Grotti, tais alterações resultaram sobretudo da "atuação firme dos sindicatos e associações de taxistas", mas não afastam debates sobre a constitucionalidade dos novos dispositivos, cujas redações incluem normas que já haviam sido propostas no passado (por exemplo, em relação à sucessão das outorgas), mas que foram vetadas pela Presidência com base 
na alegação de violação da autonomia municipal. Apesar dessa incoerência da Presidência, fato é que as alterações não foram declaradas inconstitucionais e, por isso, cabe a seguir enumerar as suas consequências em termos normativos para os serviços de táxi:

1. Os antigos "serviços públicos de transporte individual de passageiros" (redação originária do art. 12) transformam-se em "serviços de utilidade pública de transporte individual de passageiros" (redação atual do art. 12);

2. Os serviços continuam sob a competência municipal, mas não mais como modalidade de serviço público sob titularidade estatal;

3. Os serviços passam a constituir atividade econômica privada e não monopolizada, sujeita unicamente à regulação pelo poder local mediante técnicas de polícia administrativa e/ou fomento;

4. Como não são serviços públicos, mas atividade econômica regulada, em alguns Municípios, a ausência de táxis e congêneres não constituirá afronta a Constituição ou a direitos fundamentais, razão pela qual não se poderá aplicar o direito social à mobilidade (art. 60 da CF) para exigir a prestação de tais serviços;

5. Pelo mesmo motivo apontado no item anterior, o Município apenas poderá entrar no mercado de prestação de serviços de táxi e congêneres caso respeite os requisitos constitucionais de intervenção direta na atividade econômica (princípio da subsidiariedade, previsto no art. 173, caput da CF);

6. A competência municipal fica limitada ao controle de mercado (por meio de poder de polícia administrativa ou fomento como intervenção sobre a economia) e deverá abarcar a regulação de qualidade e de preços. Contudo, note-se que a redação atual do art. 12 ainda fala de tarifa. Reitere-se, porém, que se trata de preço privado com teto tabelado em cada localidade (tabelamento local de preço). Não há qualquer tarifa, em sentido técnicojurídico, pois não mais existe serviço público delegado nesse setor. Daí porque a redação do artigo revela um erro conceitual.

7. O exercício de controle de entrada dos agentes econômicos no mercado de táxi não mais se afigura compulsório. Nesse sentido, cabe exclusivamente ao Município decidir se realizará ou não controle de entrada, fixando, por exemplo, limites de prestadores. Para tanto, importante que o governo local leve em conta a tutela da livre-iniciativa, a promoção da concorrência e do bom funcionamento do mercado de transporte urbano, a 
defesa do consumidor e a proteção do ambiente natural e urbano (princípios da ordem econômica constantes do art. 170 da Constituição).

8. Caso o Município decida realizar a regulação de entrada no mercado, deverá se valer de mecanismos de polícia, como a licença ou a autorização - note-se que o art. 12-A utiliza, corretamente, o termo genérico "outorga", deixando ao Município a escolha do ato administrativo mais adequado, que pode ser mais ou menos discricionário de acordo com a legislação local. Além disso, Dinorá Grotti (2015, p. 94) também aponta a possibilidade de uso de credenciamento para viabilizar referido controle.

9. Caso decida realizar a regulação de entrada no mercado de táxis com base em seu poder de polícia, o Município deverá respeitar os princípios da Administração Pública, sobretudo o da impessoalidade. Em outras palavras, como atividade regulada, a autorização ou licença independe de realização de licitação, mas exige procedimento racional de escolha dos beneficiários do ato de admissão no mercado.

10. Instrumentos como a permissão e a concessão não devem mais ser empregados pelos Municípios para viabilizar a entrada de agentes econômicos nesse setor, já que tais institutos se restringem à função de delegação de serviços públicos (art. 175 da Constituição da República) e, como esclarecido, os serviços de táxis recaem na categoria dos serviços de interesse público.

11. A outorga para exploração do serviço de táxi, de acordo com lei municipal, poderá ser transferível a terceiro, mas observados requisitos razoáveis fixados por lei municipal e obtida a anuência do ente local competente. Em todo caso, a transferência não reiniciará o prazo de outorga.

12. A outorga para exploração também se transferirá em razão de morte aos sucessores do beneficiário originário, mas novamente mediante respeito aos requisitos legais, anuência do ente competente e continuidade do prazo originariamente estipulado para a outorga transferida.

Finalmente, em seis de julho de 2015, foi editada a Lei n. 13.146, cujo art. 119 agregou um novo artigo a respeito dos serviços de táxi e congêneres na Lei de Mobilidade Urbana, a saber:

Art. 12-B. Na outorga de exploração de serviço de táxi, reservar-se-ão 10\% (dez por cento) das vagas para condutores com deficiência. § 1으 Para concorrer às vagas reservadas na forma do caput deste artigo, o condutor com deficiência deverá observar os seguintes requisitos quanto ao veículo utilizado: I - ser de sua propriedade e por ele conduzido; e II - estar adaptado às suas necessidades, nos termos da legislação vigente. $\S 2$ ํㅡㄴ No caso de não 
preenchimento das vagas na forma estabelecida no caput deste artigo, as remanescentes devem ser disponibilizadas para os demais concorrentes.

Esse mandamento impõe aos Municípios acoplar à sua política de regulação dos "serviços de interesse público de transporte privado" ações afirmativas favoráveis a deficientes. Melhor dizendo: a lei nacional estabelece uma quota de 10\% das outorgas para esse grupo vulnerável. Contudo, há que se ter cautela na interpretação do mandamento legal, pois, como afirmado linhas atrás, a regulação de entrada de novos agentes no setor econômico examinado depende de uma escolha do Poder Legislativo local ao estabelecer a política de transporte de interesse público. Caso os entes competentes não definam regulação de entrada restritiva, ou melhor, um máximo de outorgas a ser concedido, então não haverá que se falar de qualquer tipo de quota, pois todo e qualquer indivíduo, deficiente ou não, poderá atuar no setor, contanto que atenda aos requisitos regulatórios de qualidade (incluindo propriedade do veículo e sua adaptação técnica) e respeite o teto de preço.

De outro lado, caso o Município opte pelo controle quantitativo de prestadores, aí deverá garantir os $10 \%$ das outorgas em favor de deficientes. No entanto, para se evitar que indivíduos não deficientes tentem se beneficiar indevidamente da cota e ocupar o mercado ou que deficientes usem a cota, mas transfiram o serviço a um não deficiente de modo a aniquilar a efetividade da política inclusiva, a Lei Nacional de modo bastante perspicaz exige que o beneficiário da cota demonstre possuir veículo próprio para prestação do serviço e que exerça a atividade diretamente. Reitere-se: não pode o deficiente beneficiado delegar a prestação de serviço a um não deficiente. Em sentido reverso, não se permite que o não deficiente se beneficie da cota por transferir a prestação do serviço a um deficiente. Ambas as situações são ilegais nos termos da Lei de Mobilidade.

\section{REGULAÇÃO DOS SERVIÇOS DE TÁXI: MODELOS POSSÍVEIS}

Os aspectos legais até agora tratados não esgotam a problemática regulatória do serviço em discussão. Cumpre discutir se e em que medida os Municípios estão juridicamente autorizados a adotar um sistema de regulação assimétrica, por exemplo, com o objetivo de diferenciar serviços de taxi de rua dos serviços fixos ou daqueles solicitados remotamente.

Não há dúvidas de que essa discussão ganhou relevância a partir do momento em que taxistas regulados passaram a competir com particulares que agem de modo informal e com 
suporte de aplicativos diversos disponibilizados pela internet. ${ }^{9}$ Por conta desse fenômeno, despontaram questões sobre o acesso a mercados para novos entrantes, os efeitos da ampliação dos prestadores de serviços, o desenvolvimento de melhores padrões de qualidade para os consumidores e também sobre os problemas ambientais e urbanísticos gerados pelos serviços de táxi.

No fundo, porém, a discussão que se desenrola agressivamente no mercado de serviços de transporte individual de passageiros não é nada nova. Trata-se de mais um problema urbano no qual se confrontam, de um lado, atividades econômicas forte e formalmente reguladas pelo Estado e, de outro, atividades informais que ocorrem à margem dos mandamentos jurídicos e que, por isso, libertam-se de controles de entrada, bem como de padrões estatais de qualidade e de regras administrativas fixadoras de preços.

Sob essas circunstâncias, constitui afronta à isonomia e à livre-concorrência a omissão do Poder Público local na tomada de providência para regular todos aqueles serviços de transporte que se prestam à análoga função urbanística. Entretanto, embora a omissão se revele indevida e prejudique maiormente os agentes regulados por normas de fixação de preços, de qualidade e de entrada, não se afigura juridicamente impossível que os Municípios adotem um modelo assimétrico, isto é, um modelo normativo que leve em conta as peculiaridades de cada um dos três tipos desse serviço de transporte individual de passageiros, apontado para eles regimes jurídicos diferenciados, mas assentados nas diretrizes nacionais.

Como revela o art. 12 da Lei de Mobilidade Urbana, os serviços de táxi constituem atividades econômicas de relevância pública e, como tal, cabe aos Municípios regulá-las no intuito de promover os princípios da ordem econômica e, ao mesmo tempo, concretizar a função primária da cidade. Ademais, o mesmo dispositivo legal, na redação consagrada em 2013, evidencia que não há mais obrigatoriedade de controle de entrada. Isso significa que cada Município pode adotar uma política de outorgas limitadas ou, ao revés, de outorgas sem limitação quantitativa. Imaginável igualmente é a cumulação dos dois modelos.

Frise-se bem: de acordo com a Lei de Mobilidade, nada impede que a prestação de serviço ocorra sem a outorga prévia municipal se assim o decidir o legislador local. Poder-se-ia pensar que, nessa hipótese, a regulação de qualidade, que é obrigatória pela legislação brasileira, seria prejudicada. Na prática, porém, a preocupação é facilmente combatida. A desnecessidade de

\footnotetext{
${ }^{9}$ A problemática não é exclusiva do Brasil. Sobre a situação na Alemanha, cf. o estudo de SCHRÖDER (2016, p. 42 e seguintes).
} 
outorga prévia não obsta o controle de qualidade concomitante, seja ele de natureza preventiva ou repressiva. A falta de outorga prévia tampouco inviabiliza a fixação de preço máximo. Por consequência, é perfeitamente viável que se mantenha a regulação de qualidade e de preço (tarefas municipais obrigatórias) a despeito da existência de um controle de entrada (tarefa municipal facultativa).

Por tudo isso, e - reitere-se - desde que o Município não abra mão da regulação de qualidade e da fixação de preço máximo, impostas por norma nacional vinculante de todos os entes da federação e aplicável a qualquer das três formas de prestação dos serviços de táxi, a adoção de eventual assimetria regulatória não será a princípio ilegal. É concebível e perfeitamente lícita a adoção de um modelo de convivência de serviços sujeitos a controle de entrada com outros que a ele não se submetem.

Há, contudo, que se refletir sobre os impactos positivos e negativos dos modelos regulatórios que surgem como alternativa de política ao Município, quais sejam: 1) o modelo de sujeição de todos os prestadores ao mesmo controle de entrada e à regulação formal e 2) o modelo de convivência do controle de entrada para prestadores de algumas formas do serviço de táxi com um sistema de entrada aberta para outras formas do mesmo serviço. O quadro abaixo, no intuito de contribuir à reflexão e à comparação, traz potenciais efeitos de cada opção política. ${ }^{10}$

\begin{tabular}{|c|c|}
\hline $\begin{array}{l}\text { Modelo de regulação de entrada para todos os } \\
\text { prestadores }\end{array}$ & $\begin{array}{l}\text { Modelo de convivência: entrada controlada e } \\
\text { entrada aberta }\end{array}$ \\
\hline Vantagens & Vantagens \\
\hline $\begin{array}{l}\text { 1. Padronização do regime jurídico e } \\
\text { isonomia formal } \\
\text { 2. Controle estatal do fluxo de agentes } \\
\text { econômicos } \\
\text { 3. Controle de poluição e uso das vias } \\
\text { públicas }\end{array}$ & $\begin{array}{l}\text { 1. Flexibilidade da oferta ao consumidor } \\
\text { 2. Aumento das escolhas do consumidor } \\
\text { 3. Aumento da competição }\end{array}$ \\
\hline Desvantagens & Desvantagens \\
\hline $\begin{array}{l}\text { 1. Mais barreiras jurídicas e burocráticas à } \\
\text { entrada no mercado } \\
\text { 2. Menos flexibilidade concorrencial } \\
\text { 3. Redução de opções ao consumidor }\end{array}$ & $\begin{array}{l}\text { 1. Ausência de um controle estatal } \\
\text { integral da entrada } \\
\text { 2. Risco de entrada excessiva } \\
\text { 3. Risco de redução significativa das } \\
\text { receitas dos prestadores } \\
\text { 4. Possíveis problemas ambientais e } \\
\text { urbanísticos }\end{array}$ \\
\hline
\end{tabular}

Fonte: elaboração própria

\footnotetext{
${ }^{10}$ Uma listagem de vantagens e desvantagens dos modelos de controle de entrada e de ausência de controle pode ser obtida no estudo de ESTEVES (2015, p. 21-22).
} 
Por meio dessa breve sistematização, alguns pontos conclusivos ficam evidentes: 1) existem várias opções regulatórias dos serviços de transporte privado de interesse público, sobretudo no âmbito do controle de entrada, uma vez que a regulação de qualidade e de preço está determinada em lei nacional como tarefa obrigatória do Município; 2) não há uma solução regulatória ideal e óbvia nesse setor; e 3) cada ente local, em consideração e ponderação de suas circunstâncias econômicas e territoriais, deve mensurar a geração das vantagens e desvantagens concretas de cada alternativa político-normativa, promovendo verdadeira análise de impacto regulatório sob o risco de, em vez de promover a mobilidade urbana, prejudicá-la.

\section{CONCLUSÃO}

Ainda que tardiamente, o direito brasileiro finalmente passou a se ocupar de modo intenso com o tema da mobilidade, requisito central para o cumprimento da função primária das cidades: viabilizar a interação humana por meio da garantia do espaço de fluxos na cidade. Todavia, inúmeros aspectos jurídicos necessitam ser debatidos e solucionados nessa matéria, mormente no tocante à construção de modelos regulatórios locais para os serviços de transporte urbano.

No intuito de colaborar com o debate acadêmico, empreendeu-se nesse estudo um exame das normas nacionais a reger os serviços de transporte privado de interesse público e discutiram-se de maneira sucinta os modelos regulatórios possíveis, sobretudo no tocante ao controle de entrada de prestadores de serviços de táxi. A esse respeito, buscou-se esclarecer a recente evolução da legislação nacional, as consequências jurídicas que dela resultaram e as variáveis regulatórias que devem ser consideradas pelos Municípios na avaliação de alternativas políticas.

Do quanto se investigou, merece destaque o reconhecimento jurídico da discricionariedade que a Lei de Mobilidade passou a conceder ao Poder Público local para optar ou não pela regulação de entrada de prestadores de serviços de táxi a partir de 2013. É com base nesse poder de escolha que as alternativas regulatórias se abrem e precisam ser cuidadosamente avaliadas.

O melhor modelo de política pública de transporte privado de passageiros certamente será o que se adéque à realidade local e, principalmente, o capaz de promover não a simples mobilidade, mas sim de atingir um padrão efetivo de mobilidade adequada, marcada pela segurança, simplicidade, facilidade e modicidade das formas de locomoção no tecido urbano. Somente assim, a política local poderá reverter o fenômeno da renúncia à cidade, hoje, mais do 
que nunca, resultado das graves deficiências de mobilidade urbana que afetam as cidades brasileiras.

\section{REFERÊNCIAS BIBLIOGRÁFICAS}

BEAUJEU-GARNIER, Jacqueline. Geografia urbana. Lisboa: Calouste Gulbenkian, 1997.

CARMONA, Paulo Afonso Cavichioli. Violência x Cidade: o papel do direito urbanístico na violência urbana. Brasília: Fundação Escola Superior, 2015.

CASIMIRO, Lígia Maria Silva Melo de; MELO, José Patrício Pereira. Administração Pública no século XXI: planejamento, mobilidade urbana e desenvolvimento socioeconômico. In: PONTES FILHO, Valmir; GABARDO, Emerson (org.). Problemas emergentes da Administração Pública: Anais do XXVIII Congresso Brasileiro de Direito Administrativo. Belo Horizonte: Fórum, 2015.

ESTEVES, Luiz Alberto. O mercado de transporte individual de passageiros: regulação, externalidades e equilíbrio urbano. Brasília: Departamento de Estudos Econômicos do CADE, 2015.

GROTTI, Dinorá Adelaide Musetti. Táxi. In: PONTES FILHO, Valmir; GABARDO, Emerson (org.). Problemas emergentes da Administração Pública: Anais do XXVIII Congresso Brasileiro de Direito Administrativo. Belo Horizonte: Fórum, 2015.

GUIMARÃES, Geraldo Spagno. Comentários à Lei de Mobilidade Urbana. Belo Horizonte: Fórum, 2012.

MARRARA, Thiago. Bens públicos, domínio urbano, infraestrutura. Belo Horizonte: Fórum, 2007.

Transporte público e desenvolvimento urbano: aspectos jurídicos da política nacional de mobilidade. Revista Digital de Direito Administrativo (RDDA), v. 2, n. 1, 2015.

MARTINS, Ricardo Marcondes. Soluções para a Mobilidade Urbana. PONTES FILHO, Valmir; GABARDO, Emerson (org.). Problemas emergentes da Administração Pública: Anais do XXVIII Congresso Brasileiro de Direito Administrativo. Belo Horizonte: Fórum, 2015.

PONTES FILHO, Valmir; GABARDO, Emerson (org.). Problemas emergentes da Administração Pública: Anais do XXVIII Congresso Brasileiro de Direito Administrativo. Belo Horizonte: Fórum, 2015.

SANTOS, Milton. A natureza do espaço. São Paulo: EDUSP, 2002.

SCHRÖDER, Meinhard. Ridesharing-Angebote als Herausforderung für das Personenbeförderungund das Ordnungsrecht. Revista Digital de Direito Administrativo (RDDA), v. 3, n. 1.

Trabalho enviado em 08 de abril de 2016.

Aceito em 17 de julho de 2016. 